\title{
A JUSTIÇA CONSENSUAL NA CONSTRUÇÃO DA CIDADANIA: UMA REFLEXÃO DOS 20 ANOS DE APLICAÇÃO DAS MEDIDAS ALTERNATIVAS DA LEI 9099/95.
}

\author{
THE CONSENSUS JUSTICE IN CONSTRUCTION OF CITIZENSHIP: A \\ REFLECTION OF 20 YEARS OF APPLICATION OF ALTERNATIVE MEASURES \\ OF LAW 9099/95.
}

${ }^{1}$ Pamela Ivellize Pamplona Galvao De Medeiros

\section{RESUMO}

Há duas décadas, a Lei 9099/95 consolidou novel modelo de justiça penal consensual para a os delitos de menor potencial ofensivo através da conciliação e aplicação de medidas despenalizadoras. A transação penal e a suspensão condicional do processo são as medidas despenalizadoras previstas na referida Lei. São institutos voltados à prevenção de outros delitos e à reinserção social do infrator a partir da distribuição da justiça com aplicação conjunta pelo Judiciário, Ministério Público, vítima e comunidade, representada pela sociedade civil organizada. Esse modelo de justiça restaurativa não retira o autor do fato do convívio social e proporciona o cumprimento das penas em um ambiente propício para a reflexão sobre seu papel na sociedade, seus direitos e deveres, seu compromisso consigo mesmo e com a coletividade. Esse estudo visa demonstrar que as medidas alternativas à prisão previstas na Lei 9099/95, além de resposta penal eficaz, pode atuar na construção da cidadania, como instrumento de materialização dos direitos fundamentais, com base nas experiências do programa desenvolvido no Distrito Federal a partir das parcerias entre o Ministério Público do Distrito Federal e Territórios e a Sociedade Civil.

Palavras-chave: Palavras-chaves: alternativas penais, Ministério público do distrito federal e territórios, Cidadania, Transação penal, Suspensão condicional do processo

\begin{abstract}
Two decades ago, the Law 9099/95 consolidated new consensual criminal justice model for the crimes of lesser offensive potential through conciliation and application despenalizadoras measures. The criminal transaction and the conditional suspension of the procedure are the despenalizadoras measures provided for in the Act. They are institutions aimed at preventing other crimes and social reintegration of the offender from the justice of distribution with joint application by the judiciary, prosecution, victim and community , represented by organized civil society. This restorative justice model does not remove the perpetrator from society and provides the serving of sentences in an environment conducive to reflection on their role in society, their rights and duties, your commitment to yourself and the community. This study aims to demonstrate that alternatives to imprisonment under Law 9099/95, and effective criminal act may act in the construction of citizenship, as realization instrument of fundamental rights, based on program experience developed in the Federal District from partnerships between the public prosecutor of the Federal District and Territories and civil society.
\end{abstract}

Keywords: Keywords: criminal alternatives, Public prosecution of the federal district and territories, Citizenship, Penal transaction, Conditional suspension of the proceedings

\footnotetext{
${ }^{1}$ Mestre em Direito e Políticas Públicas pelo Centro de Ensino Unificado de Brasília - UNICEUB, Brasília, Distrito Federal, (Brasil). Chefe de Setor do Ministério Público do Distrito Federal e Territórios. E-mail: pamelagalvao83@gmail.com
} 


\section{INTRODUÇÃO}

As penas e medidas alternativas à prisão são mecanismos sancionadores utilizados pela Justiça na aplicação da legislação penal em substituição à pena privativa de liberdade nos casos determinados pela lei criminal.

No Brasil, as penas e medidas alternativas penais estão previstas no artigo 43 do Código Penal e na lei 9.099/95, que instituiu os Juizados Especiais Cíveis e Criminais, utilizando as medidas alternativas como solução para os delitos de pequeno e médio potencial ofensivo.

A Lei 9099 de 26 de setembro de 1995, que completará duas décadas esse ano, constitui um elemento de modernização do direito penal brasileiro. Trata-se de um modelo de justiça consensual voltada a paz social, em que a busca pela solução do conflito é distribuída a vários atores, que representam o Estado, a comunidade e o infrator.

Os institutos despenalizadores previstos na Lei 9099/95 são a transação penal e a suspensão condicional do processo. São institutos voltados à prevenção de outros crimes e à reinserção social do infrator a partir da distribuição da justiça.

Esse modelo de justiça restaurativa não retira o autor do fato do convívio social e proporciona o cumprimento das penas em um ambiente propício para a reflexão sobre seu papel na sociedade, seus direitos e deveres, seu compromisso consigo mesmo e com a coletividade.

Essas medidas despenalizadoras, além de mecanismos sancionadores, podem tornarse instrumentos capazes de promover cidadania, quando utilizadas como meio de inserção daqueles que não raramente foram marginalizados.

As instituições da sociedade civil são imprescindíveis para a aplicação de penas e medidas alternativas. Cada rede social local, formada pelo agrupamento dessas instituições em uma determinada comunidade, tem um papel essencial. Essa atuação das redes, além de constituir um poderoso instrumento de mudança social local, contribui diretamente na execução e na efetividade das medidas alternativas, visto que promove a inclusão social das pessoas que deverão cumpri-las. 
A Constituição Federal de 1988, em seu artigo $1^{\circ}$, inciso II, ao alocar a cidadania como um dos fundamentos do Estado Democrático de Direito, conferiu maior amplitude ao seu significado. Esse conceito não se restringe aos direitos políticos, mas engloba também os direitos fundamentais.

Essa nova concepção trazida pela Carta Magna permite-nos compreender que a cidadania está vinculada à concretização dos direitos sociais, políticos e econômicos.

A promoção da cidadania é efetivada quando a medida alternativa é aplicada com esse propósito, a partir de projetos temáticos conforme a natureza do delito. Nesse sentido, a resposta estatal ao crime é orientada para construção da cidadania, para que, além de resolver o conflito com a vítima e a sociedade, o infrator possa vislumbrar outros caminhos e alternativas, que por vezes, por falta de informação e oportunidade são desconhecidos.

Esse estudo visa demonstrar que as medidas alternativas à prisão previstas na Lei 9099/95, além de resposta penal eficaz, pode atuar na construção da cidadania, como instrumento de materialização dos direitos fundamentais.

Dessa forma, o trabalho, ao tratar das Medidas Alternativas à Prisão, verificará a aplicação de outras medidas, além da prestação de serviços à comunidade a da prestação de bens, suas especificidades e características com base nas experiências do programa desenvolvido no Distrito Federal a partir das parcerias entre o Ministério Público do Distrito Federal e Territórios e a Sociedade Civil, discutindo suas funções e levantando os resultados alcançados pela aplicação das medidas alternativas.

\section{${ }^{1}$ AS MEDIDAS ALTERNATIVAS DA LEI 9099/95: UMA RESPOSTA PENAL EFICAZ E HUMANITÁRIA}

A transação penal e a suspensão condicional do processo são institutos despenalizadores previstos na Lei 9099/95. Esses institutos são voltados à prevenção de outros crimes e à reeducação do infrator a partir da distribuição da justiça com aplicação conjunta pelo Judiciário, vítima e comunidade. 
A transação penal aplica-se aos delitos de menor potencial ofensivo e pode ser entendida como um acordo entabulado entre as partes (autor do fato e Ministério Público) de aplicação imediata de penas restritivas de direitos ou multa, anterior ao oferecimento da denúncia pelo titular da ação penal. Esse acordo será válido após a chancela (homologação) judicial.

A transação penal se trata de um ato transacional e não um direito subjetivo do autor do fato. O Ministério Público transige quando deixa de oferecer denúncia e o autor do fato quando cede à perspectiva de uma absolvição.(MOREIRA, 2009, p. 77)

O Ministério Público em audiência poderá propor aplicação imediata de pena restritiva de direitos ou multas, especificadas na proposta da transação penal, quando atendidos os requisitos previstos no artigo 76 da Lei $9099 / 95^{1}$.

\footnotetext{
${ }^{1}$ Art. 76. Havendo representação ou tratando-se de crime de ação penal pública incondicionada, não sendo caso de arquivamento, o Ministério Público poderá propor a aplicação imediata de pena restritiva de direitos ou multas, a ser especificada na proposta. metade.

$\S 1^{\circ}$ Nas hipóteses de ser a pena de multa a única aplicável, o Juiz poderá reduzi-la até a

$\S 2^{\circ}$ Não se admitirá a proposta se ficar comprovado:

I - ter sido o autor da infração condenado, pela prática de crime, à pena privativa de liberdade, por sentença definitiva;

II - ter sido o agente beneficiado anteriormente, no prazo de cinco anos, pela aplicação de pena restritiva ou multa, nos termos deste artigo;

III - não indicarem os antecedentes, a conduta social e a personalidade do agente, bem como os motivos e as circunstâncias, ser necessária e suficiente a adoção da medida.

Juiz.

$\S 3^{\circ}$ Aceita a proposta pelo autor da infração e seu defensor, será submetida à apreciação do

$\S 4^{\circ}$ Acolhendo a proposta do Ministério Público aceita pelo autor da infração, o Juiz aplicará a pena restritiva de direitos ou multa, que não importará em reincidência, sendo registrada apenas para impedir novamente o mesmo benefício no prazo de cinco anos. Lei.

$\S 5^{\circ}$ Da sentença prevista no parágrafo anterior caberá a apelação referida no art. 82 desta

$\S 6^{\circ} \mathrm{A}$ imposição da sanção de que trata o $\S 4^{\circ}$ deste artigo não constará de certidão de antecedentes criminais, salvo para os fins previstos no mesmo dispositivo, e não terá efeitos civis, cabendo aos interessados propor ação cabível no juízo cível.
} 
Cumpre destacar que, ao aceitar a proposta de transação penal, o autor não está reconhecendo sua culpabilidade, mas sim evitando o doloroso processo criminal. O acolhimento da proposta não importará reincidência nem constará na certidão de antecedentes criminais.

Já a suspensão condicional do processo ocorre nos crimes em que a pena mínima cominada é igual ou inferior a um ano, conforme disposto no art. 89 da Lei 9099/95².

Nesse caso, o Ministério Público pode propor a suspensão do processo por um período de dois a quatro anos, desde que o acusado não esteja sendo processado ou não tenha sido condenado por outro crime. Sendo a proposta aceita pelo acusado e seu defensor, o Juiz suspenderá o processo, submetendo o réu a condições específicas, que podem ser a reparação do dano, apresentação mensal em juízo, ou outras medidas determinadas pelo magistrado conforme o delito e a situação pessoal do acusado.

O $\S 2^{\circ}$, do artigo 89 , ao mencionar a possibilidade de submeter o réu a outras condições, permite que os magistrados determinem medidas mais adequadas ao delito praticado, como é o exemplo de encaminhamentos para acompanhamento psicossocial, grupos de reflexão comunitária, cursos de reciclagem, participação em eventos culturais e educacionais, etc.

Esses institutos despenalizadores, além de mecanismos sancionadores, podem tornarse instrumentos capazes de promover cidadania, quando utilizados como meios de inserção daqueles que não raramente foram marginalizados.

São muitos os crimes que admitem a transação penal e a suspensão condicional do processo. A título de curiosidade, no Código Penal existe em média 175 delitos que permitem

\footnotetext{
${ }^{2}$ Art. 89. Nos crimes em que a pena mínima cominada for igual ou inferior a um ano, abrangidas ou não por esta Lei, o Ministério Público, ao oferecer a denúncia, poderá propor a suspensão do processo, por dois a quatro anos, desde que o acusado não esteja sendo processado ou não tenha sido condenado por outro crime, presentes os demais requisitos que autorizariam a suspensão condicional da pena (art. 77 do Código Penal).

$\S 1^{\circ}$ Aceita a proposta pelo acusado e seu defensor, na presença do Juiz, este, recebendo a denúncia, poderá suspender o processo, submetendo o acusado a período de prova, sob as seguintes condições:

I - reparação do dano, salvo impossibilidade de fazê-lo;

II - proibição de freqüentar determinados lugares;

III - proibição de ausentar-se da comarca onde reside, sem autorização do Juiz;

IV - comparecimento pessoal e obrigatório a juízo, mensalmente, para informar e justificar suas atividades.

$\S 2^{\circ}$ O Juiz poderá especificar outras condições a que fica subordinada a suspensão, desde que adequadas ao fato e à situação pessoal do acusado.
} 
o cabimento das medidas despenalizadoras, considerando a pena mínima abstratamente cominada (JESUS, 2009, p. 127).

Outras medidas despenalizadoras e educativas estão previstas no artigo 28 da Lei de Drogas (Lei 11343/2006) ${ }^{3}$, quais sejam: advertência sobre os efeitos das drogas; prestação de serviços à comunidade; medida educativa de comparecimento a programa ou curso educativo.

Em muitos casos do artigo 28, o autor do fato é flagrado com as drogas para seu consumo pessoal, revelando-se dependente físico. Acertadamente, a Lei preocupou-se não com o encarceramento em massa, mas em estabelecer penas alternativas à prisão e medidas educativas com a finalidade de prevenir o consumo e recuperar os usuários e dependentes.

Apesar da mídia e da opinião pública desacreditarem na eficácia das penas e medidas alternativas à prisão, alegando, inclusive que essas sanções reforçam a impunidade, a legislação e as pesquisas indicam o contrário.

Sabe-se que a política de alternativas penais é muito eficaz. As próprias Regras de Tóquio afirmam que ${ }^{4}$, os sujeitos que se submetem às penas privativas de liberdade apresentam maiores possibilidades de reincidência do que os indivíduos submetidos às medidas alternativas.

Ainda, as medidas não privativas de liberdade não restringem, tanto quanto a prisão, a liberdade do delinquente. Este não precisa deixar sua família ou comunidade, abandonar suas responsabilidades ou perder seu possível emprego. Apesar disto, os delinquentes submetidos à medida não-privativa de liberdade podem ficar sujeitos a várias condições, restrições e exigências (REGRA DE TÓQUIO, p.20).

\footnotetext{
${ }^{3}$ Art. 28. Quem adquirir, guardar, tiver em depósito, transportar ou trouxer consigo, para consumo pessoal, drogas sem autorização ou em desacordo com determinação legal ou regulamentar será submetido às seguintes penas:

I - advertência sobre os efeitos das drogas;

II - prestação de serviços à comunidade;

III - medida educativa de comparecimento a programa ou curso educativo.

$[\ldots]$

§ 50 A prestação de serviços à comunidade será cumprida em programas comunitários, entidades educacionais ou assistenciais, hospitais, estabelecimentos congêneres, públicos ou privados sem fins lucrativos, que se ocupem, preferencialmente, da prevenção do consumo ou da recuperação de usuários e dependentes de drogas.

4 A Resolução no 45/110 da Assembléia Geral das Nações Unidas refere-se às Regras Mínimas das Nações Unidas para Elaboração de Medidas Não-Privativas de Liberdade.
} 
Essa afirmação é ratificada pelos dados estatísticos. Segundo o Ministério da Justiça no caso dos condenados a pena privativa de liberdade, o índice de reincidência está a $85 \%$ enquanto entre aqueles que cumprem penas alternativas, esta porcentagem é de $5 \%$, em média.

Diante da atual crise penal vivenciada no Brasil, principalmente no que se refere à falência da estrutura penitenciária e a quantidade exorbitante de presos no país ${ }^{5}$, é necessário que as autoridades brasileiras e os órgãos públicos valorizem as alternativas penais inovando esse campo da política pública criminal.

Nesse sentido, as penas e as medidas alternativas à prisão devem ser priorizadas para a resolução dos problemas relacionados à superlotação dos presídios e à reincidência, devido seu caráter educativo e participativo. "Urge, pois, que encontremos uma solução intermediária que não privilegie o cárcere, nem espalhe a ideia da impunidade. Parece-nos que esta solução se encontra exatamente nas penas alternativas" (MOREIRA, p. 7).

A Folha de São Paulo lançou em 2014 editorial sobre o inadequado sistema carcerário brasileiro e constatou que a prisão não evita a reincidência, não ressocializa nem protege os cidadãos.

Já em relação à reincidência a partir da aplicação das medidas e penas alternativas o jornal confirma que essas sanções constituem um meio de retribuição social mais eficiente que as penas privativas de liberdade, com índice de reincidência entre 5\% e $12 \% .^{6}$

O retrato trazido pelo jornal reflete as questões trazidas à reflexão por esse trabalho ao expor o caráter desumano e estigmatizante do sistema prisional brasileiro e ao confirmar a eficiência das alternativas penais na prevenção e repressão de crimes, bem como na diminuição da superlotação carcerária.

5 O Conselho Nacional de Justiça divulgou em 2014 que o Brasil possui mais de 700 mil presos, incluindo-se os presos em regime domiciliar, ocupando a $3^{\mathrm{a}}$ posição mundial no ranking de países com a maior população carcerária do mundo, cujo modelo prisional aumenta a violência e não reintegra. Disponível em: http://www.cnj.jus.br/images/imprensa/diagnostico_de_pessoas_presas_correcao.pdf. Acesso 17 ago. 2015.

${ }^{6}$ Conforme infográficos constant no endereço eletrônico http://www1.folha.uol.com.br/opiniao/2014/01/1397304editorial-prisoes-para-quem.shtml. Acesso 28 abr. 2015. 
Vale lembrar que a justiça criminal alcança principalmente a camada mais pobre e desprovida de condições minímas de sobrevivência digna da sociedade, justamente aqueles que menos exercem seus direitos fundamentais.

A esse respeito, é a opinião interessante do Procurador de Justiça do Estado da Bahia Rômulo Andrade Moreira ao explicar que "o nosso sistema carcerário está repleto de pobres e isto não é, evidentemente, uma "mera coincidência". Ao contrário: o sistema penal, repressivo por sua própria natureza, atinge tão-somente a classe pobre da sociedade”. (MOREIRA, p. 7).

O fato das penitenciárias estarem lotadas por pessoas miseráveis economicamente e culturalmente é confirmado também por estatísticas, como no relatório da pesquisa Aplicação de penas e medidas alternativas publicado em Janeiro deste ano, elaborada pelo Instituto de Pesquisa econômica Aplicada (IPEA), fundação pública vinculada à Presidência da República, em parceria ao Departamento Penitenciário Nacional do Ministério da Justiça (DEPEN-MJ), que valida essa afirmação ${ }^{7}$.

A aplicação das penas e medidas alternativas à prisão traz consigo a possibilidade de oportunizar aos infratores trilhar um caminho diferente, construindo um novo projeto de vida longe da violência.

É nesse sentido que a aplicação das medidas alternativas deve ser pensada não apenas como meio sancionador, mas também como uma forma de trazer cidadania ao permitir o exercício dos direitos sociais básicos, dentre eles a educação.

Não retirar o autor do fato de seu convívio social e ainda permitir a participação ativa da comunidade na própria execução da medida alternativa, trata-se de uma solução humana e eficaz, garantindo a dignidade do ser humano, reservando as penas privativas de liberdade aos casos realmente necessários, bem como encorajando a coletividade a participar diretamente da justiça penal.

\footnotetext{
7 A pesquisa elaborada em conjunto com esses órgãos é de extrema relevância ao tema, pois além de validar a tese de que as prisões estão lotadas de pessoas "esquecidas" pelo Estado, objetiva a "prospecção de uma nova política criminal alternativa à prisão, a partir da elaboração de estudos diagnósticos de natureza quantitativa e qualitativa. Em relação ao grau de instrução, a mesma pesquisa aponta que: "Dentre os processos que continham informações, verificou-se que a maioria dos acusados, 75,6\%, tinha até o nível fundamental. Apenas $4 \%$ tinham nível superior, pelo menos incompleto. Em que pese a dificuldade de levantamento de informações nas varas e juizados, objetos do estudo, de um modo geral a pesquisa aponta que a na maioria dos casos os crimes foram cometidos por pessoas negras, economicamente desfavorecidas e com baixo grau de instrução.
} 
Sob essa perspectiva, é de extrema importância difundir a política de alternativas penais, sobretudo porque o regime tradicional de imposição de penas privativas de liberdade pouco contribui para a ressocialização e para evitar a reincidência dos infratores.

Dessa forma, a política de alternativas penais constitui um campo aberto as inovações para buscar atingir níveis de excelência. Para que a ampliação dessa política é necessária a articulação de diversos órgãos e o rompimento da barreira cultural ainda existente na sociedade que encara as penas e medidas alternativas como sinônimo de impunidade.

\section{A DESCONSTRUÇÃO DO PENSAMENTO INFUNDADO SOBRE A IMPUNIDADE: REPENSANDO AS MEDIDAS ALTERNATIVAS COMO UMA FORMA HUMANITÁRIA E CIDADÃ DE PUNIR}

Pode parecer piegas, mas as ideias postuladas pela política de alternativas penais ainda não são compreendidas pela comunidade como meio de justiça. Pelo contrário, a crença da comunidade é que essas medidas reforçam a impunidade.

Nesse contexto, a mídia e a opinião pública tendem ser contrárias à ampliação das penas alternativas. Tendo em vista tal cenário falacioso,é preciso envolver a sociedade na execução das medidas alternativas, de forma a entender esse tipo de resposta penal sob outra perspectiva.

Diante da existência desse pensamento infundado sobre reforço da impunidade, torna- se cada vez mais importante repensar as penas e medidas alternativas à prisão como forma de educar e de punir, a fim de cumprir a lei.

Infelizmente, a convicção que as penas e medidas alternativas não exerçam papel preventivo e sancionador não é apenas da sociedade, mas ainda é encontrada no âmbito jurídico. A pesquisa, A aplicação de penas e medidas alternativas, outrora mencionada, realizada pelo IPEA, remete essa problemática aos operadores do direito ao identificar resistência na aplicação das penas alternativas. ${ }^{8}$

\footnotetext{
${ }^{8}$ Ao visitar as varas criminais, a pesquisa menciona do IPEA identificou resistência na aplicação das penas e medidas alternativas pelos juízes de direito: “As percepções de juízes e servidores sobre as PMAs variam segundo as localidades visitadas. Em alguns momentos, as PMAs são vistas como sinônimo de impunidade, de ineficácia do sistema de justiça brasileiro. Segundo essa visão, se as PMAs foram pensadas como uma forma de desafogar as penitenciárias brasileiras, elas não estão cumprindo esse objetivo". Para esses operadores do Direito ocorreu desprestígio das medidas alternativas em razão da banalização da aplicação de cestas básicas. Existe também a questão da resistência pelos servidores públicos em oferecer informações aos pesquisadores sobre os processo: "Desde o momento da marcação da visita da equipe do Ipea com diretores de secretaria das varas criminais observou-se uma resistência por parte deles em relação à pesquisa. Essa resistência é, em geral, explicada pela pouca representatividade de processos possíveis de terem as penas substituídas nas varas criminais. Segundo os diretores, esses processos tendem a se perder no meio de outros considerados mais urgentes, especialmente aqueles que envolvem réus presos. Em varas que acumulam matéria de juizados, os processos tenderiam, ainda mais, a ficarem relegados a segundo plano, e nesse caso, como se trata de penas curtas, haveria um grande volume de prescrição". IPEA. MINISTÉRIO DA JUSTIÇA. A Aplicação de Penas e Medidas Alternativas. Sumário Executivo. Disponível em: http://www.justica.gov.br/seus-direitos/politica- penal/politicas2/alternativas-penais-anexos/pmas_sum-executivo-final-ipea_depen-24nov2014.pdf. Pag. 58. Acesso em 20 abr. 2015.
} 
Infelizmente, a convicção que as penas e medidas alternativas não exerçam papel preventivo e sancionador não é apenas da sociedade, mas ainda é encontrada no âmbito jurídico. A pesquisa, A aplicação de penas e medidas alternativas, outrora mencionada, realizada pelo IPEA, remete essa problemática aos operadores do direito ao identificar resistência na aplicação das penas alternativas. ${ }^{8}$

Por outro lado, existem juristas que concordam que as alternativas penais constituem um meio eficaz de resposta penal. Nessa mesma pesquisa há profissionais que confiam na efetividade das medidas alternativas para reduzir o encarceramento e a reincidência.

$\mathrm{Na}$ experiência jurídica brasileira, pesquisas indicam que dentre os participantes, $67,3 \%$ entendem que as penas alternativas podem ser a solução para o sistema penal brasileiro e $23,1 \%$ discordam desta assertiva. O restante, 9,6\%, concordam, mas com ressalvas; estas dizem respeito, principalmente, à efetiva execução da pena alternativa aplicada. De toda forma, a grande maioria acha que é a solução para o nosso sistema penal (76,9\%), ainda que poucos imponham algum tipo de ressalva (MOREIRA,p. 14).

\footnotetext{
${ }^{8}$ Ao visitar as varas criminais, a pesquisa menciona do IPEA identificou resistência na aplicação das penas e medidas alternativas pelos juízes de direito: "As percepções de juízes e servidores sobre as PMAs variam segundo as localidades visitadas. Em alguns momentos, as PMAs são vistas como sinônimo de impunidade, de ineficácia do sistema de justiça brasileiro. Segundo essa visão, se as PMAs foram pensadas como uma forma de desafogar as penitenciárias brasileiras, elas não estão cumprindo esse objetivo". Para esses operadores do Direito ocorreu desprestígio das medidas alternativas em razão da banalização da aplicação de cestas básicas. Existe também a questão da resistência pelos servidores públicos em oferecer informações aos pesquisadores sobre os processo: "Desde o momento da marcação da visita da equipe do Ipea com diretores de secretaria das varas criminais observou-se uma resistência por parte deles em relação à pesquisa. Essa resistência é, em geral, explicada pela pouca representatividade de processos possíveis de terem as penas substituídas nas varas criminais. Segundo os diretores, esses processos tendem a se perder no meio de outros considerados mais urgentes, especialmente aqueles que envolvem réus presos. Em varas que acumulam matéria de juizados, os processos tenderiam, ainda mais, a ficarem relegados a segundo plano, e nesse caso, como se trata de penas curtas, haveria um grande volume de prescrição". IPEA. MINISTERIO DA JUSTIÇA. A Aplicação de Penas e Medidas Alternativas. Sumário Executivo. Disponível em: http://www.justica.gov.br/seus-direitos/politica- penal/politicas2/alternativas-penais-anexos/pmas_sum-executivo-final-ipea_depen-24nov2014.pdf. Pag. 58. Acesso em 20 abr. 2015.
} 
$\mathrm{Na}$ experiência jurídica brasileira, pesquisas indicam que dentre os participantes, $67,3 \%$ entendem que as penas alternativas podem ser a solução para o sistema penal brasileiro e $23,1 \%$ discordam desta assertiva. O restante, 9,6\%, concordam, mas com ressalvas; estas dizem respeito, principalmente, à efetiva execução da pena alternativa aplicada. De toda forma, a grande maioria acha que é a solução para o nosso sistema penal (76,9\%), ainda que poucos imponham algum tipo de ressalva (MOREIRA,p. 14).

É importante difundir a ideia de que as penas alternativas não são sinônimo de impunidade, mas sim uma forma diferente e mais humana de se cumprir a pena, que beneficia não só o autor do fato, mas todo o corpo social com o trabalho e as doações.

A atual crise penal vivenciada no país com a superlotação dos presídios e a falência do sistema criminal está sendo combatida de forma errônea. A criminalização de novas condutas, o aumento das penas e a construção de novos presídios em nada contribuirá na diminuição da violência.

Por outro lado, as penas e medidas alternativas devem ser priorizadas e encaradas como meios punitivos socialmente úteis no combate à criminalidade e na construção da cidadania.

\section{${ }^{3}$ O PAPEL DA SOCIEDADE CIVIL ORGANIZADA NA CONSTRUÇÃO DA CIDADANIA A PARTIR DA EXECUÇÃO DAS MEDIDAS ALTERNATIVAS}

O Estado, sozinho, não é capaz de atender as demandas sociais. Sabe-se que um dos fatores primordiais para a modernização da Administração Pública depende do desenvolvimento e da expansão das parcerias entre o Poder Público e a Sociedade Civil. 
Da mesma forma ocorre com a execução das penas e medidas alternativas. O Estado necessita do apoio da Sociedade Civil e da comunidade para que essa política seja efetivada.

O Ministério da Justiça reconhece que para a implementação do sistema penal de alternativas penais é necessária a parceria das três esferas de poder, assim como do Ministério Público e da Sociedade Civil, afirmando "O Poder Executivo, nos três níveis de governo, deve instituir órgão responsável pela gestão da política de alternativas penais, bem como construir ou fortalecer mecanismos de participação e controle social para a formulação, execução e monitoramento dessa política, com a presença de representantes do governo e da sociedade civil, conforme consagrado pela Constituição de 1988.” (Ministério da Justiça)

Em função da celeuma existente nas ciências sociais sobre a definição de sociedade civil e terceiro setor, que em alguns momentos possuem características convergentes, apenas a título exemplificativo e didático, sem qualquer outra conotação, nesse trabalho "Sociedade Civil ou Terceiro Setor" serão considerados termos sinônimos, abarcando todas aquelas instituições sem fins lucrativos, que possuem a finalidade comum de prestar serviços de grande utilidade pública à comunidade em que atuam, caracterizando-se pela preocupação com o exercício de sua função social e da cidadania.

A própria Carta Magna prevê a participação das entidades do Terceiro Setor na esfera social, em seus artigos 150, inciso VI, alínea c, 195, $\S 7^{\circ}, 199, \S 1^{\circ}, 204$, incisos I e II ${ }^{9}$.

\footnotetext{
${ }^{9}$ Art. 150. Sem prejuízo de outras garantias asseguradas ao contribuinte, é vedado à União, aos Estados, ao Distrito Federal e aos Municípios: [...] VI instituir impostos sobre: [...]

c) patrimônio, renda ou serviços dos partidos políticos, inclusive suas fundações, das entidades sindicais dos trabalhadores, das instituições de educação e de assistência social, sem fins lucrativos, atendidos os requisitos da lei;[...] Art. 195. A seguridade social será financiada por toda a sociedade, de forma direta e indireta, nos termos da lei, mediante recursos provenientes dos orçamentos da União, dos Estados, do Distrito Federal e dos Municípios, e das seguintes contribuições sociais:[...]

$\S 7^{\circ}$ - São isentas de contribuição para a seguridade social as entidades beneficentes de assistência social que atendam às exigências estabelecidas em lei.

Art. 199. A assistência à saúde é livre à iniciativa privada.[...]
} 
A doutrina corrobora com o entendimento da imprescindibilidade da contribuição da Sociedade Civil na consecução dos objetivos estatais, sendo sua contribuição "primordial no auxílio ao Estado para atingir os objetivos constantes da Constituição e seus desdobramentos infraconstitucionais, repartindo entre si a responsabilidade da assistência social e outros direitos sociais” (TEIXEIRA, 2011, p. 34).

O Terceiro Setor compõe as redes sociais locais que atuam visando diminuir ou mesmo sanar as dificuldades enfrentadas por aquela comunidade face à ausência ou insuficiência operacional estatal.

Cada rede social local, formada pelo agrupamento dessas instituições, tem um papel único, sendo indispensável para a resolução de problemas enfrentados naquela localidade.

Essa atuação das redes, além de constituir instrumento de mudança social local, contribui para o cumprimento das medidas alternativas, pois é efetivamente nessas instituições que ocorre a prestação de serviços à comunidade e a prestação de bens, que são as medidas alternativas mais utilizadas.

A lei penal define a prestação de serviços à comunidade ou a entidades públicas como a atribuição de tarefas gratuitas ao condenado e estabelece a prestação pecuniária como sendo o pagamento em dinheiro à vítima, a seus dependentes ou a entidade pública ou privada com destinação social.

Essas entidades são mantidas a partir de doações, públicas e privadas, além do trabalho voluntário. Por isso, a parceria com o Poder Judiciário e o Ministério Público é importante para o desenvolvimento dessas instituições.

A relevância das medidas alternativas para o desenvolvimento das Instituições e seus projetos sociais já foram reconhecidas formalmente pelo Ministério Público do Distrito

\footnotetext{
$\S 1^{\circ}$ - As instituições privadas poderão participar de forma complementar do sistema único de saúde, segundo diretrizes deste, mediante contrato de direito público ou convênio, tendo preferência as entidades filantrópicas e as sem fins lucrativos.

Art. 204. As ações governamentais na área da assistência social serão realizadas com recursos do orçamento da seguridade social, previstos no art. 195, além de outras fontes, e organizadas com base nas seguintes diretrizes: I - descentralização político-administrativa, cabendo a coordenação e as normas gerais à esfera federal e a coordenação e a execução dos respectivos programas às esferas estadual e municipal, bem como a entidades beneficentes e de assistência social;

II - participação da população, por meio de organizações representativas, na formulação das políticas e no controle das ações em todos os níveis.
} 
Federal $^{10}$, que publicou recentemente em seu sítio notícia sobre instituições beneficiadas com as medidas alternativas.

As doações pecuniárias e a prestação de serviços gratuitos advindos das penas alternativas favorecem a manutenção da instituição e refletem na melhoria dos serviços prestados à comunidade assistida.

Essa contribuição originada da medida alternativa permite diminuir as dificuldades ocasionadas pela omissão de um atendimento público satisfatório, voltado para determinados segmentos sociais.

Em contrapartida, a oportunidade oferecida ao infrator de cumprir a pena no seu meio social, junto aos seus pares, além de contribuir com o desenvolvimento da sua comunidade, confirma seu status de cidadão, não fere a dignidade humana, atingindo a pena alternativa seus fins precípuos.

MIRABETE, (2007, p. 274) explica que, segundo o legislador, o conjunto de ações, medidas e atitudes que objetivam a ressocialização do condenado não deve ser tarefa exclusiva do Estado, constituindo participação da comunidade [...]. Por isso, a maior abrangência que a lei deu à aplicação dessa pena dependerá, e muito, do apoio que a comunidade der às autoridades judiciais, possibilitando a oportunidade para o trabalho do sentenciado, o que já demonstra as dificuldades do sistema adotado diante da reserva com que o condenado é encarado no meio social.

Da mesma forma, é imprescindível a contribuição da comunidade no cumprimento das medidas alternativas, em que não há condenação do infrator, mas que, através dessa alternativa é possível prevenir a reiteração criminal, reduzir a violência e trazer cidadania.

A aplicação das medidas alternativas proporciona a permanência do convívio do autor do fato com a comunidade, oferece a oportunidade de reflexão e do exercício da cidadania, auxiliando-os a encontrar caminhos alternativos para evitar uma possível reincidência e, ainda, envolve a sociedade na construção de soluções para a mudança de comportamento dos infratores.

\footnotetext{
${ }^{10}$ As prestações pecuniárias decorrentes de acordos de suspensão condicional do processo e de transações penais da PJ do Núcleo Bandeirante têm sido utilizadas para beneficiar instituições de caridade e projetos sociais da cidade. Além da semana de conscientização, foram destinados recursos para a promoção de outros eventos como o Fórum de Justiça Restaurativa: Sociedade e Justiça em Diálogo, o Curso de Mediação de Conflitos, o Encontro de Valorização dos Idosos e a reforma do Lar dos Velhinhos Francisco de Assis.
} 
É justamente nas Instituições da Sociedade Civil que se dá o cumprimento das medidas alternativas. O próprio artigo 46 do Código Penal estabelece que "a prestação de serviço à comunidade dar-se-á em entidades assistenciais, hospitais, escolas, orfanatos, e outros estabelecimentos congêneres, em programas comunitários ou estatais”.

São essas entidades que proporcionam as vagas para o trabalho comunitário e que viabilizam espaço para a restauração das relações sociais outrora corrompidas. Portanto, a atuação da sociedade civil organizada é vital para a validação da finalidade educativa e reintegrativa das medidas alternativas.

A simples conduta de escutar e de acolher os infratores sem atitudes preconceituosas e discriminatórias com foco na perspectiva educativa já está ligada ao fortalecimento de cidadania. Por diversas razões, essas pessoas, que deveriam ser ouvidas e devidamente orientadas sobre seus direitos de acordo com a visão humanística do Direito, não o são.

Esse acolhimento nas instituições da sociedade civil permite estabelecer um tipo de diálogo horizontal, longe do clima por vezes opressor existente na sala de audiências. No momento do acolhimento e do cumprimento das medidas alternativas se valida o princípio da dignidade da pessoa humana e o exercício da cidadania.

Longe do objetivo de produzir dados estatísticos cartorários relativos ao arquivamento de processos, a Sociedade Civil Organizada oferece uma intervenção positiva e orientada para o futuro, atuando para a melhoria de vida de milhares de cumpridores de penas e medidas alternativas.

Essa atuação contribui para interromper ou atenuar o ciclo de violência existente, bem como previne sua reprodução no seio familiar e comunitário.

A Sociedade Civil promove a cidadania ao colaborar para a adaptação desses indivíduos durante o período do cumprimento da medida alternativa.

Ao receber os autores do fato para prestação de serviços à comunidade, a instituição compromete-se em fornecer condições favoráveis ao bom desenvolvimento do trabalho a ser executado, que deve ser adequado ao seu perfil e habilidades. 
Não estigmatizar nem expor o beneficiário a situações que envolvam atividades insalubres e perigosas e acompanhar sua frequência são atitudes necessárias ao processo de reintegração social.

Na prestação pecuniária é importante que a Instituição, além de requerer a compra de determinado bem, explique ao autor a importância de sua aquisição, de forma que exista maior envolvimento do infrator com as necessidades daquela comunidade. Todas as atitudes, por mais simples que sejam, fortalecem o vínculo do autor do fato com a comunidade na qual está inserido.

A atuação do terceiro setor está principalmente voltada à educação, saúde e cultura, o que permite o direcionamento do cumprimento da medida alternativa de acordo com a conduta delitiva praticada. Essas entidades são essenciais ao processo de reintegração do infrator porque trazem excelentes resultados, quando os projetos relacionados ao cumprimento das medidas alternativas estão voltados à promoção social.

A medida alternativa aplicada sob o viés temático é mais efetiva, pois, além do caráter sancionatório e preventivo, reeduca e oferece mecanismos de tratamentos capazes de evitar a reincidência, porque facilitam a compreensão do caráter inadequado do comportamento do autor e são legítimas e adequadas como sanção. O benefício desse processo reflete diretamente na comunidade, sendo necessário que a política de alternativas penais seja pensada a partir da conduta delituosa. 


\section{${ }^{4}$ APLICAÇÃO DAS MEDIdAS ALTERNATIVAS EM PROJETOS TEMÁticos A PARTIR DA INFRAÇÃO PENAL: REFLEXÕES ACERCA DO TRABALHO REALIZADO NO MPDFT}

A característica da infração praticada deve ser tratada com a finalidade de se encontrar a solução mais adequada ao caso concreto e para que a medida possa atingir o objetivo esperado.

Sob essa perspectiva, as medidas alternativas aplicadas devem ser voltadas à natureza do delito. Nem sempre a prestação de serviços à comunidade ou a prestação pecuniária são as medidas mais eficazes na conscientização do autor do delito e na reintegração social.

A aplicação das medidas alternativas sob o viés do contexto social e das características das infrações permite a adoção de medidas mais adequadas ao caso concreto, por meio da participação em programas na área da saúde, educação, cultura, esportes, etc, como meios complementares ao cumprimento das medidas alternativas.

O Ministério Público do Distrito Federal e Territórios (MPDFT), através da Secretaria Executiva de Medidas Alternativas (CEMA) ${ }^{11}$ e de vários projetos voltados aos beneficiários das medidas despenalizadoras demonstra seriedade e perspicácia no tratamento das medidas alternativas.

A Secretaria Executiva de Medidas Alternativas (CEMA) e seus setores regionais, são responsáveis pelo assessoramento ao Membros do MPDFT na indicação das medidas alternativas mais apropriadas ao caso concreto. A CEMA também é responsável por firmar parcerias com as instituições para encaminhamento dos beneficiários das medidas alternativas.

A CEMA possui em sua estrutura setores regionais, denominados Setor de Controle e Acompanhamento às Medidas Alternativas (SEMA`s), que atuam em todas as satélites e são responsáveis pelo controle e acompanhamento das medidas alternativas aplicadas na respectiva circunscrição judiciária, bem como pela formação de parcerias locais.

11 Todos os dados estatísticos apresentados nessa pesquisa foram extraídos do SMA - Sistema de Medidas Alternativas, em que dados são inseridos após atuação do Promotor de Justiça. Para maiores informações sobre a CEMA e o SMA: http://www.mpdft.mp.br/portal/index.php/conhecampdft-menu/secretaria-executivade-medidas-alternativas-mainmenu-276. Acesso em 22 jun 2015. 
Além dos setores regionalizados, a CEMA possui em sua estrutura o Setor de Consolidação de Informações (SETCOI), responsável pelo Sistema de Medidas Alternativas (SMA) e o Setor de Gerenciamento de Medidas Alternativas para Delitos de Meio Ambiente, Ordem Urbanística e Patrimômio Público (SETEMA).

O Setor de Consolidação de Informações (SETCOI) é um setor especializado responsável pela qualidade e divulgação das informações disponibilizadas no SMA (Sistema de Medidas Alternativas). Os dados são alimentados pelos servidores lotados nos SEMA's regionais e através do sistema é possível mapear diversos tipos de informações acerca das medidas alternativas aplicadas no Distrito Federal.

Atualmente, a CEMA possui em quadro o total de 40 servidores, divididos conforme quadro abaixo.

Quantidade de servidores

\begin{tabular}{|c|c|}
\hline Secretaria Executiva & 1 \\
\hline $\begin{array}{c}\text { Secretaria Administrativa } \\
\text { SETEMA }\end{array}$ & 1 \\
\hline $\begin{array}{c}\text { Setor de Medidas de Meio Ambiente - } \\
\text { SETCOI }\end{array}$ & 1 \\
\hline Setores de Consolidac̃o de Informações - & 35 \\
\hline
\end{tabular}

Os servidores que atuam nos SEMA's das satélites são responsáveis pelo atendimento ao autor do fato. Nesse atendimento, realiza-se entrevista socioeconômica, onde há diálogo, evitando-se o preconceito e a estigmatização. Ao analisar os fatores sociais e econômicos do autor, busca-se a medida mais adequada ao caso.

Além disso, o servidor orienta o autor do fato sobre as medidas despenalizadores, as consequências de seu descumprimento e como se dará o acompanhamento das medidas alternativas.

Nesse momento, o servidor atua como agente transformador da realidade social, pois sensibiliza o autor do fato no sentido de encarar a prestação de serviço gratuito como uma oportunidade de contribuir para o desenvolvimento da comunidade. 
Esse contato é de extrema relevância, pois permite que infrator seja ouvido e exponha suas dificuldades e frustrações. Além disso, esse primeiro contato é complementado pelo atendimento realizado na Instituição parceira, onde de fato, ocorre o cumprimento da medida alternativa.

Toda essa estrutura existente no âmbito do MPDFT já demonstra a seriedade do órgão no tratamento dado às penas e medidas alternativas, que reconhece a importância desse trabalho para o futuro, na prevenção de novas condutas delituosas e na reiteração criminal.

Os servidores do SEMA também são responsáveis por firmar as parcerias com as Instituições, bem como realizar visitas semestrais e orientá-las sobre o procedimento acerca das penas e medidas alternativas.

Ressalta-se que o CEMA-MPDFT possui atualmente 379 Instituições parceiras, que atuam disponibilizando vagas, cursos, acompanhamento psicossocial, dentre outras atividades voltadas ao cumprimento das penas e medidas alternativas previstas na Lei 9099.

Apenas nos primeiros 4 meses de 2015 foram registrados mais de 1000 atendimentos, que resultaram em 52.463 horas de prestação de serviço à comunidade e em mais de 300 encaminhamentos para participação em palestras e cursos. Vale conferir:

Instituições parceiras em 2015

\begin{tabular}{|c|c|}
\hline Quantidade de Instituições Parceiras & 379 \\
\hline Prestação de Serviços à Comunidade & 52.463 horas \\
\hline Educação, Palestras e Cursos & 317 encaminhamentos \\
\hline
\end{tabular}

Quantidade de relatórios produzidos em 2015

\begin{tabular}{|c|c|}
\hline Número de Processos Recebidos & 1206 \\
\hline TE - Termos de Encaminhamento & 658 \\
\hline $\begin{array}{c}\text { REEM - Relatório de Execução de } \\
\text { Medidas Alternativas }\end{array}$ & 560 \\
\hline RIS - Relatório de Investigação Social & 85 \\
\hline Notificações Escritas & 344 \\
\hline Notificações por Telefone & 759 \\
\hline
\end{tabular}


Em anos anteriores, o Sistema de Medidas Alternativas - SMA, do MPDFT indica que no prazo de 3 anos, entre 2012 e 2015, foram beneficiados no Distrito Federal 14.110 autores do fato e réus com as penas e medidas alternativas previstas na Lei 9099-95, dentre elas foram aplicadas 7730 transações penais (art. 76) e 6122 suspensões condicionais do processo (art. 89). ${ }^{12}$

\begin{tabular}{|c|c|c|c|}
\hline ANO & $\begin{array}{c}\text { Transação } \\
\text { Penal }\end{array}$ & $\begin{array}{c}\text { Suspensão Condicional - } \\
\text { SURSIS }\end{array}$ & TOTAL \\
\hline 2012 & 2767 & 1293 & $\mathbf{4 0 6 0}$ \\
\hline 2013 & 2591 & 2228 & $\mathbf{4 8 1 9}$ \\
\hline 2014 & 2372 & 2601 & $\mathbf{4 9 7 3}$ \\
\hline TOTAL & 7730 & 6122 & $\mathbf{1 3 8 5 2}$ \\
\hline
\end{tabular}

Importante destacar também quais as medidas alternativas mais aplicadas no mesmo período.

\begin{tabular}{|c|c|c|c|c|c|c|c|c|c|}
\hline Medida & $\begin{array}{l}\text { Advertência } \\
\text { em Audiência }\end{array}$ & $\begin{array}{l}\text { Condições } \\
\text { Obrigatórias } \\
\text { a do SURSIS }\end{array}$ & $\begin{array}{l}\text { Cumprimento } \\
\text { de Condiçã } \\
\text { Obrigação }\end{array}$ & $\begin{array}{l}\text { Educação, } \\
\text { Curso ou } \\
\text { Palestra }\end{array}$ & \begin{tabular}{|c|} 
Plano de \\
Recuperação \\
der Ârea \\
Degradada
\end{tabular} & $\begin{array}{c}\text { Prestação } \\
\text { de Bens }\end{array}$ & $\begin{array}{l}\text { Prestação } \\
\text { de } \\
\text { Serviços }\end{array}$ & $\begin{array}{c}\text { Programa } \\
\text { de Saúde }\end{array}$ & $\begin{array}{l}\text { Reparação } \\
\text { de Dano à } \\
\text { vítima }\end{array}$ \\
\hline 2012 & 15 & 577 & 19 & 698 & 25 & 1500 & 1904 & 887 & 45 \\
\hline 2013 & 20 & 1536 & 31 & 966 & 22 & 1765 & 2460 & 1135 & 60 \\
\hline 2014 & 5 & 1912 & 68 & 944 & 23 & 1602 & 2899 & 854 & 73 \\
\hline
\end{tabular}

12 Informações constantes do retrato interativo do Sistema de Medidas Alternativas do MPDFT. 
Observa-se que a prestação de serviço à comunidade e a prestação de bens são as medidas mais aplicadas. Todavia, percebe-se que existe a preocupação de encaminhar os infratores a determinados programas de saúde e à participação em cursos e palestras. O gráfico a seguir ilustra de forma apropriada essa preocupação no âmbito do órgão:

\section{Medidas Aplicadas de 2012 a 2014}

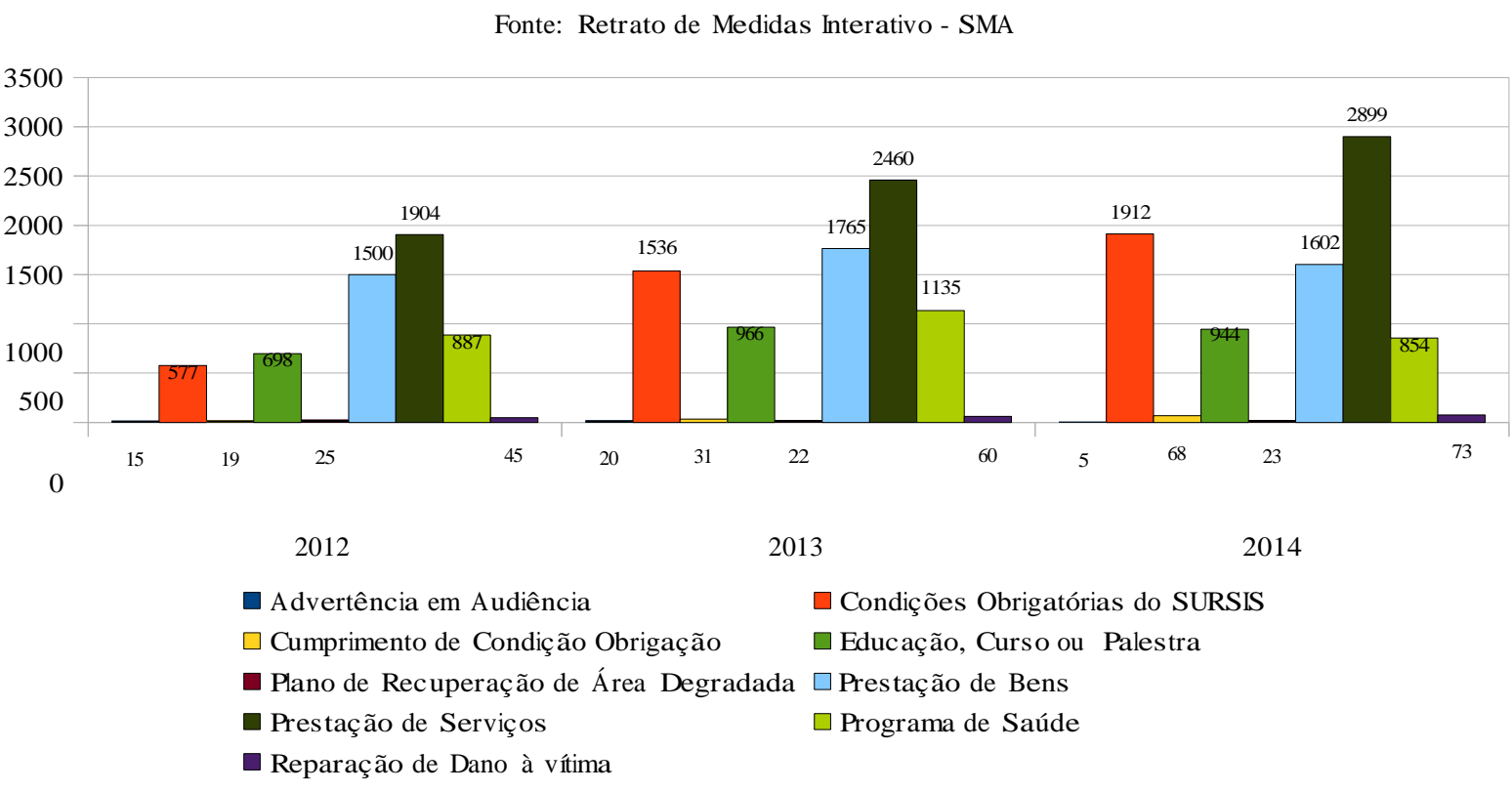

Isso indica que as intervenções ou medidas geralmente tem sido aplicadas levando-se em consideração as características do autor e o tipo de delito praticado.

A aplicação e execução temática das medidas alternativas permitem que através do direito de punir do Estado, mais do que um mecanismo de sanção, elas sejam um meio de efetivação dos direitos sociais e consequentemente de concretização da cidadania.

No MPDFT há experiências de sucesso nesse sentido. No caso dos delitos de trânsito, por exemplo, além da antiga parceria com o DETRAN para o curso de reciclagem, existe o projeto "Valorize a Vida no Trânsito", que realiza palestras para os autores de delitos de trânsito beneficiados pela transação penal e suspensão condicional do processo após audiência judicial.

As palestras ocorrem periodicamente e consiste em uma das condições para o cumprimento da medida e extinção do processo. O projeto que existe há cinco anos no órgão apresentou ótimos resultados no ano de 2014, o que levou a Administração Superior do órgão a estender essa prática a todas as circunscrições judiciárias de Brasília . Vale a pena conferir: 
-5 palestras com a participação de 324 infratores de trânsito em 2014

- 324 transações penais, que resultaram na extinção ou suspensão do processo

- Identidade visual do projeto

- Selo "valorize a vida no trânsito"

- Certificado de participação na palestra

- 1000 cartilhas "Segurança no Trânsito",13

Além da participação na palestra, para que a pessoa cumpra a sanção alternativa adequada, que ajude na sua ressocialização, ela passa, primeiramente, pelo atendimento no SEMA, que faz a entrevista socioeconômica e uma avaliação. O infrator que possui problemas com alcoolismo e se envolveu no acidente de trânsito, por exemplo, pode ser encaminhado a um grupo de Alcoólicos Anônimos, receber assistência de um psicólogo, se for o caso, e ainda, ter de prestar serviços comunitários em hospitais para se conscientizar das consequências que os acidentes causam às vítimas.

Essas ações são de extrema importância, pois permitem que o trânsito seja encarado com seriedade e respeito às leis, além disso contribuem na reeducação e reabilitação dos condutores.

Recentemente, o MPDFT criou o projeto "Você tem outra opção", que consiste numa atividade a ser desenvolvida por um psicólogo voltada aos beneficiários da transação penal e suspensão condicional do processo, visando a conscientização desses infratores sobre a importância de não cometer delitos para manutenção de uma vida social saudável e livre de conflitos.

A criação desse projeto demonstra novamente o reconhececimento da importância das penas e medidas alternativas para sistema penal brasileiro. Inicialmente a palestra está concentrada em uma circunscrição judiciária, mas certamente será reconhecida institucionalmente pela sua relevância no possível processo de conscientização do autor do fato que consequentemente diminuirá a reincidência.

Também merece destaque o trabalho realizado pelas Promotorias de Justiça do Meio Ambiente (PRODEMA`s) com o auxílio do SETEMA. Da mesma forma que os SEMA's regionais, o SETEMA é responsável pelas entrevistas com os autores do fato para analisar o perfil socioeconômico, a fim de sugerir a medida mais adequada, e por firmar parcerias com instituições públicas e privadas para cumprimento das medidas alternativas.

\footnotetext{
${ }^{13}$ Para maiores informações sobre os programas do MPDFT apresentados nessa pesquisa acesse www.mpdft.mp.br.
} 
No caso das condutas lesivas ao meio ambiente (Lei 9605 de 1998), a parceria entre o MPDFT e o Parque Nacional merece elogios porque atende a finalidade da Lei. O curso de formação socioambiental é oferecido aos autores de delitos ambientais e objetiva sensibilizar o autor do fato, oferecendo oportunidade de formação socioambiental, permitindo assim, ampliar a percepção e a compreensão dos mecanismos de sustentabilidade da vida na Terra, sobretudo, das ameaças à qualidade de vida, bem como discutir alternativas e soluções que possam contribuir para gerar mudança de seus conceitos, valores, decisões e atitudes.

Geralmente são ministradas palestras referentes a Noções de Educação Ambiental, Cerrado e Meio Ambiente, Planejamento em Unidades de Conservação com enfoque em Uso Público, Introdução à Legislação Ambiental e Práticas Sensoperceptivas.

Vale ressaltar que as PRODEMA's e o SETEMA também trabalham com o PRAD Plano de Recuperação de Área Degradada, que consiste em um estudo ambiental que visa o reestabelecimento de um ecossistema que foi degradado por uma pessoa física ou jurídica.

Outro tratamento diferenciado está relacionado ao artigo 28 da Lei de drogas que trata do porte de drogas para consumo próprio. Esses autores são encaminhados para participação em palestras de conscientização sobre o prejuízo causado pelo uso das substâncias entorpecentes, para o NA (Narcóticos Anônimos), ou ainda, para tratamento ambulatorial e psicossocial nos casos mais graves em outras instituições parceiras e órgãos públicos.

Em 2007, o MPDFT firmou parceria com o Setor de Atenção ao Usuário de Álcool e Drogas (SEAD) do Hospital Universitário de Brasília (HUB) para o Programa de Atendimento ao Usuário e ao Dependente de Drogas, que oferecia tratamento diferenciado aos usuários de entorpecentes.

O programa visando a reinserção social dos usuários de drogas adota critérios humanizados, quais sejam:

1. Evitar a desqualificação moral do usuário ou estigmatizá-lo.

2. Possibilitar a plena participação do usuário na construção da estratégia de tratamento.

3. Dar maior ênfase na pessoa e não na droga.

4. Despertar no usuário a consciência do uso de drogas como forma de escapismo.

5. Trabalhar noções de saúde e qualidade de vida como as maiores virtudes de uma pessoa. 
Esse projeto foi reconhecido nacionalmente, sendo premiado pelo Ministério da Justiça durante o VI CONEPA em abril de 2010 como uma das 15 melhores práticas de medidas alternativas do país.

Em relação ao crime de maus-tratos, previsto no artigo 136, do Código Penal, o MPDFT possui parcerias com Universidades no campo da psicologia para atendimento individual e em grupo.

No caso da formação dos grupos para autores de maus tratos, trabalha-se o contexto da prática do delito, a fim de permitir a reflexão sobre as atitudes cometidas que muitas vezes se refletem em excesso de coerção ou abuso do poder familiar.

Esse tipo de intervenção, na maioria dos casos, surte mais efeito do que a prestação de serviço à comunidade ou a prestação de bens, pois além de promover a reflexão, permite desenvolver nos pais estratégias e habilidades para a educação dos filhos, por vezes interrompendo o ciclo de violência familiar existente.

Note-se que a concretização de todas essas ações depende da parceria com a Sociedade Civil, daí sua relevância na execução das medidas alternativas. As instituições, no contato direto com o autor do fato, atentam-se a perspectiva educativa e aos direitos de cidadania.

Além de executar as medidas alternativas, essas instituições são responsáveis por trazer cidadania a essas pessoas quando permitem a elas o acesso aos seus direitos sociais básicos, nas áreas da saúde, educação, lazer, cultura, etc.

As parcerias temáticas como mecanismo de conscientização sobre a ilicitude do fato e as consequências danosas à comunidade, além do resultado positivo à sociedade, é possível utilizar o ius puniendi estatal como meio de efetivar os direitos sociais.

Apesar da política de alternativas penais já ser praticada de acordo com a natureza do crime em diversos programas no âmbito do MPDFT, isso não significa que não há espaço para inovação e revisão dessa política institucional.

Considerando a eficácia da política de alternativas penais e a estrutura já existente, o MPDFT deve investir na implantação de novos projetos temáticos visando a adoção de novos mecanismos de intervenção para os diversos tipos de infração penal. 
Sem dúvida, a cooperação dos servidores que atuam com essa temática pode oferecer elementos indispensáveis para uma melhor condução dessas atividades. Isso porque esses servidores atuam diariamente com os infratores e as instituições, estabelecendo um elo de comunicação entre os agentes envolvidos, podendo facilmente identificar as dificuldades existentes no processo de reintegração social, subsidiando a atuação dos membros na resolução desses problemas.

A articulação com a rede social, o estabelecimento de parcerias e o atendimento aos infratores incluem-se entre as atribuições desses servidores. São imputações que exigem um determinado perfil e capacitação continuada.

O investimento em capacitação dos servidores e das instituições que atuam com os cumpridores de alternativas penais, bem como na realização de pesquisas científicas voltadas para temática, deve ser priorizado pelo órgão.

A participação dos servidores em seminários, workshops e congressos traz contribuições ao órgão na produção de novas diretrizes e elementos estratégicos para atuação dos membros.

Impende destacar que os Setores de Medidas Alternativas já obtiveram sucesso em suas atividades de monitoramento e acompanhamento das medidas alternativas. Em alguns casos, após o cumprimento da medida alternativa em sua integralidade e consequente arquivamento do processo, os antigos prestadores de serviços gratuitos, além de não mais delinquirem, se tornaram voluntários nas instituições em que realizaram trabalho comunitário.

Um autor do fato que era cabeleleiro, após ser entrevistado, foi encaminhado a uma creche. Após cumprir as horas determinadas em audiência, retornou ao SEMA para entregar sua folha de frequência e, muito animado, relatou aos servidores que as crianças faziam fila para ter a oportunidade de fazer um corte igual ao do Neymar. Esse trabalho foi tão gratificante e especial, que ele se tornou voluntário e mensalmente visitava a creche para cortar os cabelos das crianças.

Muitos são os casos de infratores que trabalham como pedreiros, pintores, vidraceiros, eletricista, e outras profissões que podem colaborar com a manutenção das instalações das entidades parceiras. Os trabalhos gratuitos e as prestações pecuniárias já foram responsáveis pela construção ou reforma de muitas unidades. 
O acompanhamento da medida alternativa e a sensibilização realizada em conjunto pelos servidores do SEMA e pela Instituição contribuíram diretamente na reinserção social desses indivíduos, trazendo-lhes novas perspectivas de vida.

Fomentar a alimentação correta do SMA (Sistema de Medidas Alternativas) para realização de coleta de dados fidedignos a fim de promover banco de dados sobre as práticas realizadas no órgão, permite divulgar as boas práticas em todo território nacional.

Novas parcerias temáticas devem ser realizadas. A título de exemplo uma parceria interessante pode ser feita para os delitos de pichação com o programa "Picasso não pichava" ${ }^{14}$, da Polícia Militar do Distrito Federal, em que se ensina a arte do grafite.

Uma outra parceria conveniente seria voltada ao delito de maus-tratos, com a "Escola de Pais" do UNICEUB, que consiste em uma atividade do Cenfor de Psicologia para desenvolver nos pais habilidades e estratégias para a educação dos filhos e debater temas das áreas de desenvolvimento infantil e de relações entre pais e filhos ${ }^{15}$.

O programa esporte à meia-noite ${ }^{16}$, que existe em várias circunscrições judiciárias, pode atender a demanda dos infratores que não tem disponibilidade de trabalhar no período diurno. Além de possibilitar a prestação de serviços à comunidade no período noturno, pode

${ }^{14}$ Picasso não Pichava é um programa comunitário que tem como foco reduzir a criminalidade infanto-juvenil. É destinado à execução de atividades culturais e artísticas para crianças, adolescentes e jovens envolvidos ou não com práticas delituosas.Foi criado em 13 de junho de 1999, oficializado pelo Decreto no 21.782 de 05 de dezembro de 2000, e atualmente instituído pelo Decreto $\mathrm{n}^{\circ} 33.245$ de 05 de outubro de 2011, como um subprograma do Pró-Comunidade (Programa Segurança Comunitária em Ação) que unifica a gestão dos programas, projetos e ações sociais da Secretaria de Estado de Segurança Pública do Distrito Federal, realizados por intermédio da Subsecretaria de Programas Comunitários - SUPROC.Tem como objetivo prevenir o envolvimento de crianças, adolescentes e jovens com a criminalidade, a discriminação, a intolerância, a violência e ao uso do crack e de outras drogas. Assim como construir, reeducar e desenvolver o potencial artístico e cultural, principalmente daqueles envolvidos com a prática da pichação ou outro meio de danificação de edificação ou monumento urbano.

15 Escola de pais: Treinamentos e Estratégias para a Educação dos Filhos em Grupos Psicoativos. Debate áreas de desenvolvimento infantil e de relações entre pais e filhos.

$16 \mathrm{O}$ programa esporte à meia-noite está vinculado à Secretaria de Segurança Pública do Distrito Federal e atende centenas de crianças e adolescentes de baixa renda combatendo a criminalidade infantil por meio do esporte. Tem como objetivo geral combater, de forma preventiva, a criminalidade juvenil, por meio do desenvolvimento de ações esportivas, de qualificação profissional e de lazer, destinadas à expressão de seus valores culturais e voltadas à construção de sua cidadania; Propiciar a maior integração dos jovens em suas famílias por meio de informação e participação dos pais e responsáveis nas atividades do projeto; Promover a interação do sistema de segurança pública com as comunidades beneficiadas pelo projeto, de modo a difundir sua nova Desenvolver atividades esportivas, culturais e educativas para adolescentes, no período noturno, com o objetivo de diminuir a criminalidade juvenil. 
envolver o autor do fato no universo esportivo, dando-lhes novos caminhos para preencher o tempo ocioso.

A transação penal e a suspensão condicional do processo, além de mecanismos de sanção, podem se tornar meios de construção de cidadania. Firmar convênios com o Sistema S para cursos profissionalizantes, EJA, PRONATEC, dentre outros programas estatais pode beneficiar essas pessoas que se envolveram com delitos de pequeno ou médio potencial ofensivo, muitas vezes por falta de oportunidade e informação. Então porque não oferecer, para aqueles que se interessam, a oportunidade de estudar ou crescer profissionalmente?

A cumulação das medidas alternativas com a participação em cursos profissionalizantes, na educação de jovens e adultos, dentre outros, pode ser uma política de atuação inovadora a ser pensada e desenvolvida pelo órgão.

Um novo olhar para as penas e medidas alternativas como instrumentos de acesso à assistência social, saúde, educação, lazer, cultura, direitos humanos e até geração de empregos e renda permite a plena realização da cidadania daqueles que foram não raramente marginalizados. Promover a cidadania é, inclusive, é um dos objetivos estratégicos do MPDFT, cujo resultado para a sociedade é justamente a cidadania fortalecida. ${ }^{17}$

\section{CONCLUSÃO}

Considerando a eficácia da política de alternativas penais, o país deve construir ou fortalecer mecanismos de participação e controle social para a formulação, execução e monitoramento dessa política, com a presença de representantes do governo e da sociedade civil, conforme consagrado pela Constituição de 1988.

As políticas públicas de alternativas penais devem ser orientadas a partir dessa nova perspectiva, objetivando a realização plena dos direitos de cidadania que compreende os direitos civis, sociais, políticos, individuais coletivos e difusos.

${ }^{17}$ Disponível em: http://www.mpdft.mp.br/portal/index.php/gesto-estratgica-sectionmenu-423/526-objetivosestrategicos . Acesso em 29 jun. 2015. 
Sob essa orientação está pautada a atuação do Ministério Público do Distrito Federal e Territórios na aplicação da Lei 9099-95 e os institutos despenalizadores da transação penal e suspensão condicional do processo.

Embora já exista no órgão uma estrutura consolidada para a aplicação e o acompanhamento das medidas alternativas, isso não significa que não há espaço para melhorias e projetos inovadores.

Novos programas e projetos temáticos podem ser implantados após pesquisas e estudos, bem como os projetos já existentes podem ser renovados para atingir níveis de excelência.

Um novo olhar mais humanitário e cidadão para as penas e medidas alternativas é fundamental para a inovação dessa política no âmbito do MPDFT. Além de um meio de sanção, as medidas alternativas previstas na Lei 9099-95 devem ser voltadas para a melhoria das condições de vida das pessoas envolvidas, garantindo, assim, o pleno exercício da cidadania.

Para isso, forçoso o investimento por parte do órgão em estudos e pesquisas científicas, participação dos servidores em congressos, palestras, workshops, cursos de pósgraduação.

Ademais disso, a abertura de espaço para diálogo com os atores sociais que vivenciam a execução das medidas alternativas é fundamental para o entendimento das práticas estabelecidas no órgão, buscando identificar e sanar as dificuldades para reconstruir e repensar visando a melhoria dos trabalhos executados.

A cumulação das medidas alternativas com a participação em cursos profissionalizantes, na educação de jovens e adultos, dentre outros, pode ser uma política de atuação inovadora a ser pensada e desenvolvida a fim de fortalecer a cidadania.

Lembrando que as penas e medidas alternativas tratam-se de uma solução humana e eficaz, garantindo a dignidade do ser humano, sendo de extrema importância difundir a política de alternativas penais, reservando as penas privativas de liberdade aos casos realmente necessários. 


\section{REFERÊNCIAS}

BRASIL. Constituição da República Federativa do Brasil. Disponível em: <http://www.planalto.gov.br/ccivil_03/constituicao/constituicaocompilado.htm>.Acesso em 8 mai 2015.

ESCOLA DE PAIS, UNICEUB. Disponível em: <http://www.uniceub.br/noticias/noticiasinstitucionais/1o-semestre-2015/escola-de-pais.aspx >. Acesso em 1 jul. 2015.

FOLHA DE SÃO PAULO. Editorial: prisões pra quem? Disponível em: <http://www1.folha.uol.com.br/opiniao/2014/01/1397304-editorial-prisoes-para-quem.shtml> Acesso em 28 abr. 2015.

FONAPE. Fórum Nacional de Alternativas Penais. Disponível em: <http://s.conjur.com.br/dl/fonape-enunciados.pdf. > Acesso em 29 abr. 2015.

IPEA. MINISTÉRIO DA JUSTIÇA. Relatório de Aplicação de Penas e Medidas Alternativas. Disponível em: <http://www.justica.gov.br/seus-direitos/politica-penal/politicas-2/pesquisas> Pag. 7. Acesso em 27 abr. 2015.

JESUS, Damásio de. Lei dos Juizados Especiais Criminais Anotada. São Paulo, 2009.

Juristas defendem penas alternativas em vez de prisão. Disponível em: $<$ http://agenciabrasil.ebc.com.br/geral/noticia/2014-10/juristas-encarceramento-nao-e-unicaresposta-para-o-crime> . Acesso em 28 abr. 2015.

Lei 9099/95. Disponível em: 〈wwww.planalto.gov.br>. Acesso em 8 de mai. 2015.

MINISTÉRIO DA JUSTIÇA. Alternativas Penais - Diretrizes. Disponível em: <http://www.justica.gov.br/seus-direitos/politica-penal/politicas-2/diretrizes > . Acesso em 20 abr. 2015.

MINISTÉRIO DA JUSTIÇA. Política de Alternativas Penais. Disponível em: <http://portal.mj.gov.br/> Acesso em 20 abr. 2015.

MINISTÉRIO PÚBLICO DO DISTRITO FEDERAL E TERRITÓRIOS. Medidas Alternativas beneficiam projetos sociais e instituições de caridade no Núcleo BandeirantePenais - Diretrizes. Disponível em:

$<$ http://www.mpdft.mp.br/portal/index.php/comunicacao-menu/noticias/noticias2015/noticias-2015-lista/7472-medidas-alternativas-beneficiam-projetos-sociais-einstituicoes-de-caridade-do-nucleo-bandeirante >. Acesso em 25 jun. 2015. 
MINISTÉRIO PÚBLICO DO DISTRITO FEDERAL E TERRITÓRIOS: MP EFICAZ. Disponível em: <http://www.mpdft.mp.br/portal/index.php/conhecampdft-menu/programas-eprojetos-menu/mp-eficaz-projetos-institucionais/6705-programa-oferece-tratamentoterapeutico-para-usuarios-de-drogas> . Acesso em 29 jun. 2015.

MINISTÉRIO PÚBLICO DO DISTRITO FEDERAL E TERRITÓRIOS: OBJETIVOS ESTRATÉGICOS. Disponível em: <http://www.mpdft.mp.br/portal/index.php/gestoestratgica-sectionmenu-423/526-objetivos-estrategicos> . Acesso em 29 jun. 2015.

MOREIRA, Rômulo Andrade. O Conselho Nacional de Justiça e as Penas Alternativas. Disponível em: <http://www.conteudojuridico.com.br/artigo,o-conselho-nacional-de-justicae-as-penas-alternativas,52337.html > . Acesso em 28 abr. 2015.

MOREIRA. RÔMULO DE ANDRADE. Penas Alternativas. Disponível em: <http://www.bu.ufsc.br/penas_alternativas.html. > Acesso em 4 mai. 2015.

MOREIRA, Rômulo de Andrade. Juizados Especiais Criminais. Bahia, 2009.

Penas Alternativas. Disponível em: <http://asmego.org.br/2012/08/13/assunto-e-tema-dereportagem-de-o-popular/> . Acesso em 27 abr. 2015.

PROGRAMA ESPORTE À MEIA NOITE. Disponível em: <http://www.ssp.df.gov.br/servicos/programas-comunitarios/esporte-a-meia-noite/278projeto-piloto.html> . Acesso em 1 jul. 2015.

PROJETOS PICASSO NÃO PICHAVA. Disponível em: <http://www.ssp.df.gov.br/sobre-asecretaria/subsecretarias/siosp/itemlist/category/159-conhe\%C3\%A7a-o-projeto.feed? type=atom>. Acesso em 1 jul. 2015.

Resolução no 45/110 da Assembléia Geral das Nações Unidas refere-se às Regras Mínimas das Nações Unidas para Elaboração de Medidas Não-Privativas de Liberdade. Disponível em: <http://direitoshumanos.gddc.pt/3_6/IIIPAG3_6_11.htm> Acesso em 1 jul. 2015.

TEIXEIRA, Josenir. O Terceiro Setor em perspectiva. Da Estrutura à Função Social. Belo Horizonte, 2011.

XXII Conferência Nacional dos Advogados. Disponível em: <http://conferencia.oab.org.br/temario.html >. Acesso em 28 abr. 2015. 